\title{
The use of numerical simulations to improve a new analytical chip formation model
}

\author{
Ferdinando Salvatore ${ }^{1, a}$, Tarek Mabrouki ${ }^{2}$ and Hédi Hamdi ${ }^{1}$ \\ 1 Université de Lyon, ENISE, LTDS, UMR 5513 CNRS, 58 rue Jean Parot, 42023 Saint-Étienne Cedex 2, France \\ 2 LAMCOS UMR 5259 CNRS/Université de Lyon INSA Lyon, 18-20, rue des Sciences, 69621 Villeurbanne Cedex, France
}

Received 10 February 2012, Accepted 5 November 2012

\begin{abstract}
In this paper, an analytical approach is proposed to model chip formation in the case of turning process. Numerical simulations of chip genesis are performed in order to fit efficiently the proposed analytical model. In particular, cutting edge radius influence, temperature and internal stresses distribution are studied using finite element modelling. Numerical model setting is made with experimental and literature data using forces and chip thickness.
\end{abstract}

Key words: Numerical / analytical / cutting model / chip formation / cutting edge radius influence

Résumé - Utilisation des simulations numériques pour l'amélioration d'un nouveau modèle analytique de coupe orthogonale. Dans cet article scientifique est présentée une nouvelle approche de modélisation de la formation de copeau en coupe orthogonale. La modélisation et la simulation numérique par éléments-finis sont utilisées pour vérifier certaines hypothèses de la modélisation analytique et investiguer les contraintes et leur distribution dans les bandes de cisaillement. L'influence du rayon d'arête sur la coupe est également prise en compte. Les extrapolations de certaines tendances numériques seront utilisées en tant qu'équations dans le modèle analytique. Le calage du modèle numérique est fait avec les résultats expérimentaux en termes d'épaisseur de copeau et efforts de coupe.

Mots clés : Numérique / analytique / modélisation de la coupe / formation de copeau / rayon d'acuité d'arête

\section{Introduction}

Turning and in general material removal processes are widely used in different industries to cut different engineering parts. Usually the optimization of these processes is often made by expensive experimental methods and not able to be extrapolated to other machining configurations. To overcome these drawbacks numerical simulations have been carried out by many researchers but the major inconvenience of those methods are the long computing time, the high cost of numerical software etc.

For all these reasons, in the manufacturing industry, a high interest in analytical methods like that of Merchant and Lee and Schaffer [1-3] is usually researched because there are very practical and simple to use. Gilormini and Felder [4], Oxley [5], Moufki et al. [6] and more recently Molinari [7] have proposed the computation of the temperatures and shear zones thicknesses but the methodology to obtain those values is in general long and complicated for the industrial community. In fact the

${ }^{a}$ Corresponding author: ferdi3@free.fr differential equations present in those thermo-mechanical models need time to be solved and also, in the same way, some parameters are not easy to find in bibliography.

For all these reasons, the aim of the present paper is to present a methodology to calculate the major numbers of variables of chip formation (forces, temperatures, contact length, ... ). Here the equations can be directly used by engineers.

The proposed analytical modelling of the chip formation is performed using universal mechanical formulation and balance. It is improved by numerical simulations and verified with experimental data. Moreover the cutting edge radius influence is taken into account in order to correctly analytically compute variables when the cutting radius of the tool is used.

First the experimental tests, the machines, materials employed and the measured data like forces and chip thickness are presented. Then, the new analytical modelling is presented. Numerical simulation using ABAQUS Explicit is developed in order to identify more accurately 


\section{Nomenclature}

\begin{tabular}{|c|c|}
\hline$A, B, c, m, n, T_{\text {empmelt }}$ & Johnson and Cook parameters. \\
\hline$b$ & Cutting depth $[\mathrm{m}]$ \\
\hline$d_{1}$ & Primary shear zone thickness $[\mathrm{m}]$ \\
\hline$d_{2}$ & Secondary shear zone thickness $[\mathrm{m}]$ \\
\hline$h_{c}$ & Chip thickness $[\mathrm{m}]$ \\
\hline$h$ & Uncut chip thickness $\left[\mathrm{m} \cdot \mathrm{rev}^{-1}\right]$ \\
\hline$F_{x}$ & Cutting force $[\mathrm{N}]$ \\
\hline$F_{y}$ & Feed force $[\mathrm{N}]$ \\
\hline$l_{1}$ & Length of the primary shear zone $[\mathrm{m}]$ \\
\hline$l_{c}$ & Contact length between tool and chip $[\mathrm{m}]$ \\
\hline$Q_{1}$ & Plastic energy converted into heat in the primary shear zone $[\mathrm{J}]$ \\
\hline$Q_{2 \mathrm{~g}}$ & Plastic energy converted into heat in the secondary shear zone (sliding-sticky sub zone) $[\mathrm{J}]$ \\
\hline$Q_{2 \mathrm{~s}}$ & Plastic energy converted into heat in the secondary shear zone (sticky zone) $[\mathrm{J}]$ \\
\hline$N_{1}$ & Normal force on the primary shear zone $[\mathrm{N}]$ \\
\hline$N_{2}$ & Normal force on the secondary shear zone $[\mathrm{N}]$ \\
\hline$T_{1}$ & Tangential force in the primary shear zone $[\mathrm{N}]$ \\
\hline$T_{2}$ & Tangential force in the secondary shear zone $[\mathrm{N}]$ \\
\hline$R$ & Tool cutting edge radius $[\mathrm{m}]$ \\
\hline$T_{\text {emp0 }}$ & Room temperature $[\mathrm{K}]$ \\
\hline$T_{\text {emp1 }}$ & Temperature in the primary shear zone $[\mathrm{K}]$ \\
\hline$T_{\text {emp10 }}$ & Initial temperature in the workpiece $[\mathrm{K}]$ \\
\hline$T_{\text {emp2g }}$ & Temperature in the secondary shear zone (sliding-sticky sub zone) $[\mathrm{K}]$ \\
\hline$T_{\mathrm{emp} 2 \mathrm{~s}}$ & Temperature in the secondary shear zone (sticky sub zone) $[\mathrm{K}]$ \\
\hline$\Delta T_{\text {emp2g }}$ & Heat generated in the secondary shear zone (sliding-sticky sub zone) $[\mathrm{K}]$ \\
\hline$\Delta T_{\mathrm{emp} 2 \mathrm{~s}}$ & Heat generated in the secondary shear zone (sticky sub zone) $[\mathrm{K}]$ \\
\hline$V_{g}$ & Sliding speed in the tool-chip interface $\left[\mathrm{m} . \mathrm{s}^{-1}\right]$ \\
\hline$V_{t}$ & Chip evacuation speed $\left[\mathrm{m} \cdot \mathrm{s}^{-1}\right]$ \\
\hline$V_{1}$ & Primary shear zone sliding speed $\left[{\left.\mathrm{m} . \mathrm{s}^{-1}\right]}^{-1}\right.$ \\
\hline$W_{1}$ & Primary shear zone volume $\left[\mathrm{m}^{3}\right]$ \\
\hline$W_{2 \mathrm{~g}}$ & Secondary shear zone volume (sliding-sticky sub zone) $\left[\mathrm{m}^{3}\right]$ \\
\hline$W_{2 \mathrm{~s}}$ & Secondary shear zone volume (sticky sub zone) $\left[\mathrm{m}^{3}\right]$ \\
\hline Zone 1 & Primary shear zone \\
\hline Zone 2 & Secondary shear zone \\
\hline$\delta_{1}$ & Heat partition coefficient in the primary shear zone \\
\hline$\delta_{2}$ & Heat partition coefficient in the secondary shear zone \\
\hline$\delta_{2 \mathrm{~g}}$ & Heat partition coefficient in the secondary shear zone (sticky-sliding sub zone) \\
\hline$\delta_{2 \mathrm{~s}}$ & Heat partition coefficient in the secondary shear zone (sticky sub zone) \\
\hline$\Phi$ & Primary shear zone angle $\left[^{\circ}\right]$ \\
\hline$\gamma$ & Cutting angle $\left[^{\circ}\right]$ \\
\hline$\gamma^{*}$ & Equivalent cutting angle $\left[^{\circ}\right]$ \\
\hline$\gamma_{d 0}^{\bullet}$ & Reference shear strain rate used in Johnson-Cook model $\left[\mathrm{s}^{-1}\right]$ \\
\hline$\gamma_{d 1}$ & Strain at primary shear zone \\
\hline$\gamma_{d 1}^{\bullet}$ & Strain rate at primary shear zone $\left[\mathrm{s}^{-1}\right]$ \\
\hline$\gamma_{d 2 \mathrm{~g}}$ & Strain at secondary shear zone (sliding-sticky sub zone) \\
\hline$\gamma_{d 2 \mathrm{~s}}$ & Strain at secondary shear zone (sticky sub zone) \\
\hline$\gamma_{d 2 \mathrm{~g}}^{\bullet}$ & Strain rate at secondary shear zone (sliding-sticky sub zone) $\left[\mathrm{s}^{-1}\right]$ \\
\hline$\gamma_{d 2 \mathrm{~s}}^{\bullet}$ & Strain rate at secondary shear zone (sticky sub zone) $\left[\mathrm{s}^{-1}\right]$ \\
\hline$\mu$ & Friction coefficient at the tool-chip interface \\
\hline$\sigma_{\mathrm{n} 1}$ & Primary shear zone normal stress $[\mathrm{MPa}]$ \\
\hline$\sigma_{\mathrm{n} 2}$ & Secondary shear zone normal stress $[\mathrm{MPa}]$ \\
\hline$\sigma_{n 2 \max }$ & Maximum normal stress at secondary shear zone $[\mathrm{MPa}]$ \\
\hline$\sigma_{n 1 \max }$ & Maximum normal stress at primary shear zone $[\mathrm{MPa}]$ \\
\hline$\tau_{1}$ & Primary shear zone tangential stress $[\mathrm{MPa}]$ \\
\hline$\tau_{2 \mathrm{~g}}$ & Secondary shear zone tangential stress (sliding-sticky sub zone) $[\mathrm{MPa}]$ \\
\hline$\tau_{2 \mathrm{~s}}$ & Secondary shear zone tangential stress (sticky sub zone) [MPa] \\
\hline
\end{tabular}



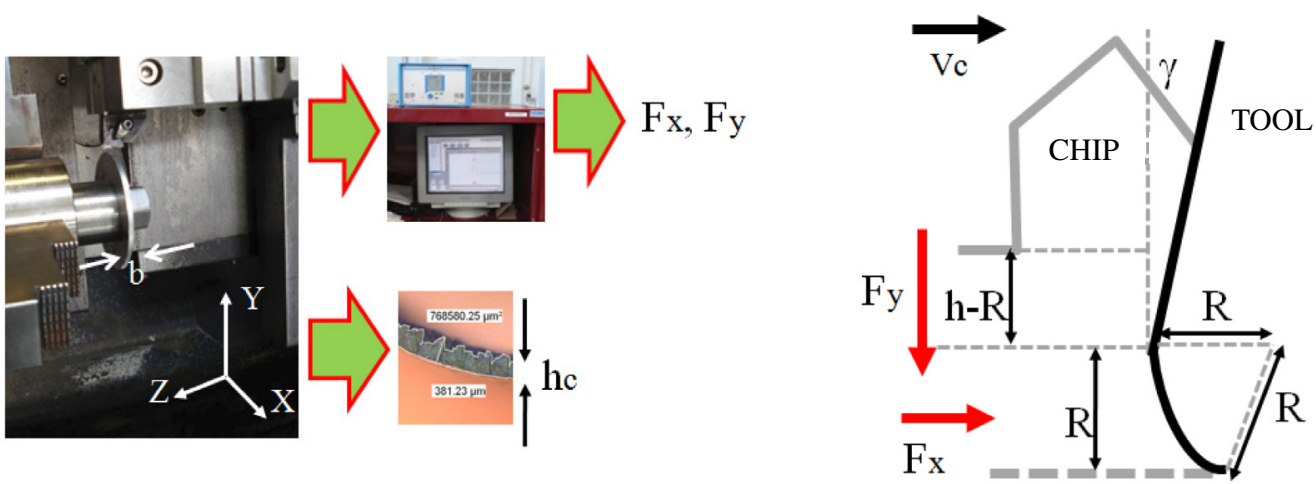

Fig. 1. Experimental test procedure.

Table 1. Experimental values of horizontal $\left(F_{x}\right)$ and vertical $\left(F_{y}\right)$ forces and the chip thickness $h_{c}$ in the case of machining of AISI 4140, tool in carbide material $(R=30 \mu \mathrm{m}), h=$ $0.15 \mathrm{~mm}, b=3 \mathrm{~mm}, \gamma=0^{\circ}$.

\begin{tabular}{ccccc}
\hline$V_{c}\left[\mathrm{~m} \cdot \mathrm{min}^{-1}\right]$ & $F_{x}[\mathrm{~N}]$ & $F_{y}[\mathrm{~N}]$ & $h_{c}[\mathrm{~mm}]$ & $\Phi\left[^{\circ}\right]$ \\
\hline 42 & 1118 & 563 & 0.31 & 26 \\
126 & 1052 & 495 & 0.22 & 33 \\
378 & 998 & 412 & 0.18 & 37 \\
\hline
\end{tabular}

physical phenomena and obtain new equations to improve the analytical model.

\section{Experimental tests}

In this section the experimental cutting tests are presented. In order to replicate orthogonal cutting conditions, the machining operation was done on a disc with a diameter of $70 \mathrm{~mm}$ and a thickness $(b)$ of $3 \mathrm{~mm}$, which presents in the same time the cutting depth (Fig. 1).

$V_{\mathrm{c}}$ is the cutting speed, $h_{\mathrm{c}}$ the chip thickness, $h$ the uncut chip thickness, $\gamma$ the cutting angle. $F_{x}$ is the horizontal force, $F_{y}$ the vertical one. The cutting tool is in a carbide grade (ref. TPKN 1603 PP R SM30) with cutting edge radius $R$ of $30 \mu \mathrm{m}$ and the machined material is a steel alloy AISI 4140.

The values of $b$ and $R$ were chosen to minimize ploughing effects and elastic phenomena in order to have a real cutting process [8]. Measures of forces in $(x, y, z)$ are done with dynamometer Kistler 9257 A with natural signal frequency $2000 \mathrm{~Hz}$. Details of forces, chip thickness and primary shear angle are presented in the Table 1.

In this table it is possible to capture that $F_{x}$ is conversely proportional to the cutting speed, what is typical in the case of softening materials. Similarly, $F_{y}$ has the same trend but in this case there is also the contribution of friction. In fact, for high cutting speed, $\mu$ at the tool chip interface is lower as it is showed in Zemzemi works [9]. Both softening metal effects and the reduction of the friction coefficient can explain the trend of the primary shear angle $\Phi$, computed with Equation (1)

$$
h_{c}=\frac{h(\cos \gamma \cos \Phi-\sin \gamma \sin \Phi)}{\sin \Phi}
$$

\section{Analytical model}

Orthogonal cutting represented by a $2 \mathrm{D}$ model is considered in the present study. The regime is considered stationary and the chip rigid. Deformations are supposed to be uniform and concentrated in the primary and secondary shear zone. $d_{1}$ and $d_{2}$ are thickness of those zones.

In order to present a simple approach, it is supposed that the cutting process is made with a virtual tool, having a cutting edge radius $R=0 \mu \mathrm{m}$ (Figs. 2 and 3 ), and an equivalent cutting angle $\gamma^{*}$ (Figs. 2 and 3). This last variable takes into account cutting edge radius effects.

The latter angle is the summation of 2 contributions. The first one is the local cutting angle $\gamma_{R}$ caused by the cutting radius; its action is localized in the layer $R(\mathrm{GO})$.

The second one is the contribution of the cutting angle $\gamma$ in the layer $(h-R)(\mathrm{HG})$.

Based on geometric considerations the equivalent cutting angle $\gamma^{*}$ is given by Equation (2).

$$
\begin{aligned}
\gamma^{*}=-\left(\frac{R}{h}\right) & \gamma_{R}+\left(\frac{h-R)}{h}\right) \gamma=-\left(\frac{R}{h}\right) \\
& \times \operatorname{Arctan}\left(\frac{R-\sqrt{2 R}}{R}\right)+\left(\frac{h-R)}{h}\right) \gamma
\end{aligned}
$$

where $\gamma_{R}$ is the angle created between GO and the vertical. From Equation (2) it is noted that, when $R$ tends to 0 or when $h$ is very high, $\gamma^{*}$ is close to $\gamma$. In the opposite situation, if $h=R$ the equivalent cutting angle is equal to $-45^{\circ}$.

Chip is considered rigid and $N_{1}$ and $\Phi$ can be expressed when balances of forces applied to chip in static mechanical are written (Eqs. (3) and (4)).

$$
\begin{aligned}
& N_{1} \sin (\Phi)+T_{1} \cos (\Phi)=T_{2} \sin (\gamma *)+N_{2} \cos (\gamma *) \\
& N_{1} \cos (\Phi)-T_{1} \sin (\Phi)=T_{2} \cos (\gamma *)-N_{2} \sin (\gamma *)
\end{aligned}
$$

Contact length can be expressed with torque balances around the tip of the tool, but it is necessary to know stresses distributions in the primary and secondary shear zones (Fig. 4), as it will be showed in the numerical section.

In this last figure $l_{1}$ is the primary zone length, $\sigma_{\mathrm{n} 1}$ and $\tau_{1}$ are respectively the normal and the tangential stresses 

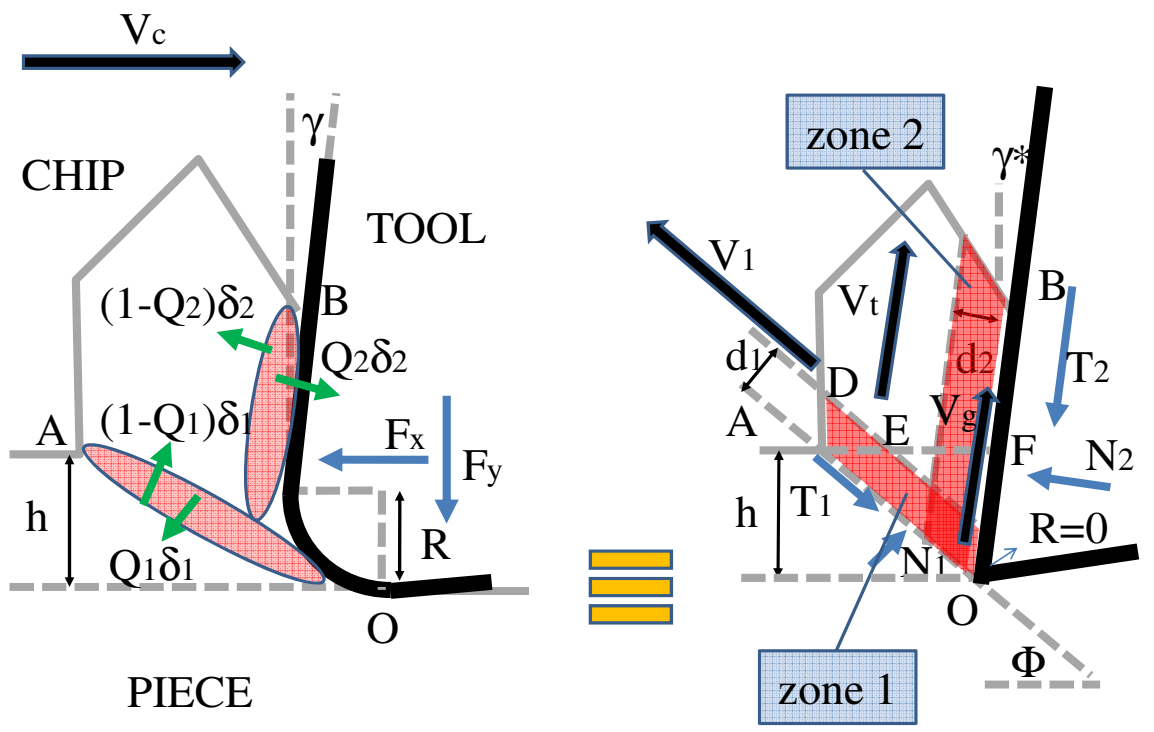

PIECE

Fig. 2. Representation of the material removal process.

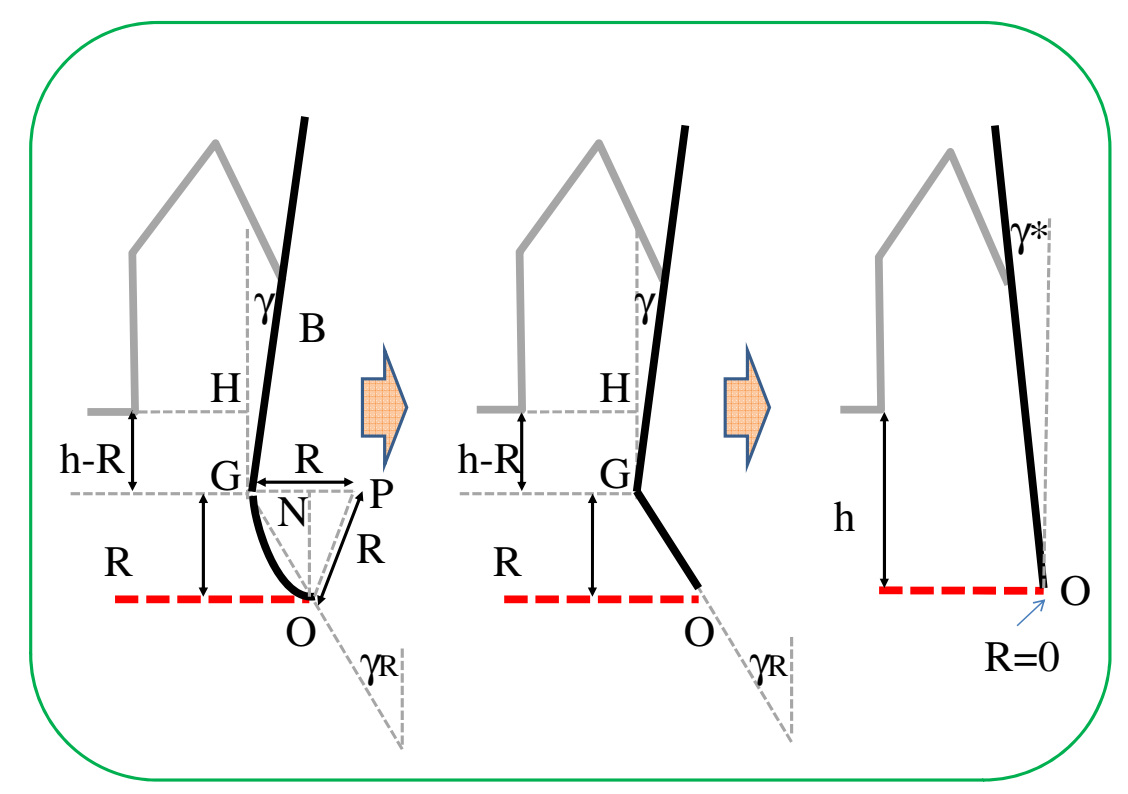

Fig. 3. Definition of the equivalent cutting angle $\gamma^{*}$.

in this zone. $\sigma_{\mathrm{n} 2}$ is the normal stress in the secondary shear zone. Finally, $l_{c}$ is the contact length at the interface tool-chip.

Having now a stress distribution applied to the chip, it is possible to write the torque balance around the tip of the tool O (Eq. (5)).

$$
\begin{aligned}
N_{1} \frac{0.6 h}{b \sin (\Phi)}=\frac{\sigma_{n 2 \max } h^{2}}{2 \cos \left(\gamma^{*}\right)}+\frac{\sigma_{n 2 \max }}{2} & {\left[\frac{l_{c} \cos \left(\gamma^{*}\right)+2 h}{3 \cos (\gamma *)}\right] } \\
\times & {\left[\frac{l_{c} \cos \left(\gamma^{*}\right)-h}{\cos \left(\gamma^{*}\right)}\right] }
\end{aligned}
$$

In Equation (5) $\sigma_{n 2 \max }$ is the maximal stress value in the secondary shear zone. The triaxiality is high in the region of the piece close to the tip of the tool. The normal stress value in the primary shear zone is close to the normal stress value in the secondary one, which will be demonstrated in the numerical section.

From those considerations, and according to the next numerical study, it is possible to extract new simple Equations (6) where the maximum value of the normal stress $\sigma_{n 2 \max }$ is a function of the tangential one $\tau_{1}$. Consequently the normal force $N_{2}$ in the secondary shear zone is a function of $\tau_{1}$ (Eq. (7)).

$$
\begin{aligned}
\sigma_{n 1 \max } & =\sigma_{n 2 \max }=\sqrt{3} \tau_{1} \\
N_{2} & =b \int_{0 .}^{l_{c}} \sigma_{\mathrm{n} 2} \mathrm{~d} l=\frac{\sqrt{3}}{2} b \tau_{1}\left[l_{c}+\frac{h}{\cos \left(\gamma^{*}\right)}\right]
\end{aligned}
$$

It is now necessary to compute $T_{1}$ and $T_{2}$ in order to find all the variables of the study. Concerning $T_{1}$ it is supposed 


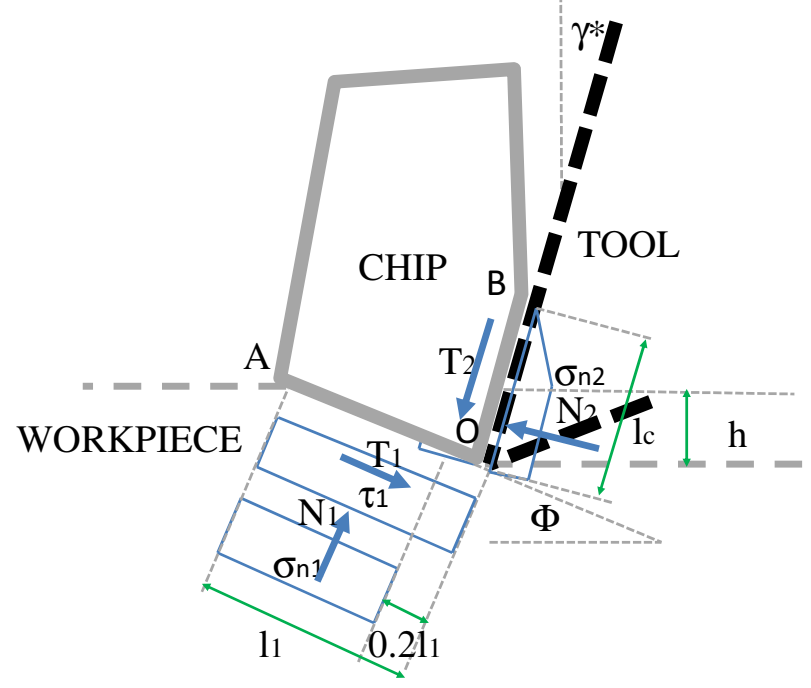

Fig. 4. Stresses and forces distributions applied to the chip.

to be a simple shear in the primary zone (Eq. (8)).

$$
T_{1}=\tau_{1} l_{1} b=b \frac{h}{\sin (\Phi)} \tau_{1}
$$

$\tau_{1}$ is computed with Johnson and Cook law [10] (Eq. (9)).

$$
\begin{aligned}
\tau_{1}=\left[\frac{A}{\sqrt{3}}+\frac{B \gamma_{d 1}^{n}}{\sqrt{3}^{n+1}}\right] & {\left[1+C \operatorname{Ln}\left(\frac{\dot{\gamma}_{d 1}}{\dot{\vartheta}_{d 0}}\right)\right] } \\
\times & {\left[1-\left(\frac{T_{\text {emp } 1}-T_{\text {emp0 }}}{T_{\text {empmelt }}-T_{\text {emp } 0}}\right)^{m}\right] }
\end{aligned}
$$

where $A, B, n, C, m$ and $\gamma_{d 10}^{\bullet}$ are Johnson and Cook parameters [13]. $T_{\text {empmelt }}$ and $T_{\text {emp0 }}$ are respectively the melt temperature of the steel and the room temperature. The unknown parameters in Equation (9) are only $\gamma_{d 1}$, $\gamma_{d 1}^{\bullet}$ and $T_{\text {emp } 1}$.

According to Figure 2, the strain in zone 1 is computed with Equation (10) and the strain rate with Equation (11).

$$
\begin{array}{r}
\gamma_{d 1}=\frac{D E}{d_{1}}=\frac{1}{\tan (\gamma *+\pi / 2-\Phi)}+\frac{1}{\tan (\Phi)} \\
\dot{\gamma}_{d 1}^{\bullet}=\frac{V_{1}}{d_{1}} \quad \text { with } \quad V_{1}=\frac{V_{C}}{\cos (\Phi)+\sin (\Phi) \tan \left(\gamma^{*}\right)}
\end{array}
$$

Those last 2 equations are similar to Moufki's ones [11,12] but here the cutting angle takes into account the cutting edge radius. $V_{1}$ is the shearing speed along the primary shear zone (Fig. 2).

In order to compute the temperature in the primary shear zone, the unitary deformed volume $W_{1}$ in this zone is evaluated by Equation (8). It is supposed that the plastic deformation is concentrated in this volume. The plastic strain is considered uniform in the thickness $d_{1}$.

$$
W_{1}=a_{p} l_{1} d_{1}
$$

$D E$ is the displacement (Fig. 2) caused by the force $T_{1} ; Q_{1}$ is the plastic energy converted into heat in the primary shear zone (Eq. (13)).

$$
Q_{1}=0.9 T_{1} D E
$$

In this last equation it is considered that only $90 \%$ of the plastic energy is converted into heat [13].

Consequently the primary shear zone temperature $T_{\text {emp1 }}$ is computed with Equation (14) using the definition of specific heat.

$T_{\mathrm{emp} 1}=T_{\mathrm{emp} 10}+\left(1-\delta_{1}\right) \frac{Q_{1}}{\rho W_{1} C_{p}}=T_{\mathrm{emp} 10}+\left(1-\delta_{1}\right) \frac{0.9 \gamma_{d 1} T_{1}}{\rho l_{1} C_{p}}$

$T_{\text {emp10 }}$ is the initial temperature in the work piece and $\delta_{1}$ is the partition heat coefficient considered to be zero in this paper. In fact for modern cutting technology $\left(V_{c}>100 \mathrm{~m} \cdot \mathrm{min}^{-1}\right)$ the adiabatic hypothesis in zone 1 can be adopted [14] as it will be possible to verify in the numerical section.

The last variable to be computed to solve the system is the friction force at the interface tool-chip $T_{2}$.

A sticky contact from the point F to O (Fig. 2) is supposed and a sticky-sliding contact from $\mathrm{F}$ to $\mathrm{B}$. It is also supposed that the thickness of the secondary shear zone $d_{2}$ is equal to $d_{1}$. Consequently, the strain and the strain rate are given by the following equations, respectively:

$$
\begin{aligned}
\gamma_{d 2 \mathrm{~s}} & =\frac{h}{\cos (\gamma *) d_{2}} \\
\gamma_{d 2 \mathrm{~s}} & =\frac{V_{t}}{d_{2}}=\frac{V_{c} \sin (\Phi)}{\cos (\Phi-\gamma *) d_{2}}
\end{aligned}
$$

In the same way as was computed $T_{\text {emp1, the heat }}$ $\Delta T_{\text {emp2s }}$ generated in the sticky zone in the secondary shear zone is now suggested (Eq. (17)).

$$
\begin{aligned}
\Delta T_{\mathrm{emp} 2 \mathrm{~s}}=\left(1-\delta_{2 \mathrm{~s}}\right) \frac{Q_{2 \mathrm{~s}}}{\rho W_{2 \mathrm{~s}} C_{p}}=( & \left.1-\delta_{2 \mathrm{~s}}\right) \frac{0.9 \gamma_{d 2 \mathrm{~s}} \tau_{2 \mathrm{~s}}}{\rho C_{p}} \\
& =T_{\mathrm{emp} 2 \mathrm{~s}}-T_{\mathrm{emp} 1}
\end{aligned}
$$

$\delta_{2 \mathrm{~s}}$ is the heat partition coefficient between the tool and the work piece, supposed equal to zero in this study (adiabatic conditions). $T_{\text {emp2s }}$ is the temperature in this sub zone and $T_{\text {emp } 1}$ is the initial temperature. In this case it is the primary shear temperature, displaced in zone 2 during the chip evacuation. $\tau_{2 \mathrm{~s}}$ is the tangential sticky shear stress in zone 2 computed with Johnson and Cook law (Eq. (18)).

$$
\begin{aligned}
\tau_{2 \mathrm{~s}}=\left[\frac{A}{\sqrt{3}}+\frac{B \gamma_{d 2 \mathrm{~s}}^{n}}{\sqrt{3}^{n+1}}\right]\left[1+C \operatorname{Ln}\left(\frac{\hat{\gamma}_{d 2 \mathrm{~s}}}{\boldsymbol{\gamma}_{d 0}}\right)\right] \\
\times\left[1-\left(\frac{T_{\mathrm{emp} 2 \mathrm{~s}}-T_{\mathrm{emp} 0}}{T_{\text {empmelt }}-T_{\mathrm{emp} 0}}\right)^{m}\right]
\end{aligned}
$$

In the BF zone (Fig. 2), a sticky-sliding contact is assumed. Here the strain and the strain rate are not constant as considered in the sticky zone. In fact it is supposed that close to the point $\mathrm{F}$ the contact is still sticky 
$\left(V_{g}=0\right)$ and in the point B totally sliding $\left(V_{g}=V_{t}\right)$. In order to easily compute variables of this zone, an only sticky contact is supposed in the half distance BC. In the other half distance a totally sliding contact is considered $(\mu=0)$. Consequently:

$$
\begin{gathered}
\gamma_{d 2 \mathrm{~g}}=\frac{1}{2 d_{2}}\left(l_{c}-\frac{h}{\cos (\gamma *)}\right) \\
\gamma_{d 2 \mathrm{~g}}=\frac{V_{t}}{d_{2}}=\frac{V_{c} \sin (\Phi)}{\cos (\Phi-\gamma *) d_{2}}
\end{gathered}
$$

The heat generated in the sticky-sliding sub zone $\Delta T_{\text {emp2g }}$ is presented in Equation (21).

$$
\begin{aligned}
\Delta T_{\mathrm{emp} 2 \mathrm{~g}}=\left(1-\delta_{2 \mathrm{~g}}\right) \frac{Q_{2 \mathrm{~g}}}{\rho W_{2 \mathrm{~g}} C_{p}}= & \left(1-\delta_{2 \mathrm{~g}}\right) \frac{0.9 \gamma_{d 2 \mathrm{~g}} \tau_{2 \mathrm{~g}}}{\rho C_{p}} \\
& =T_{\mathrm{emp} 2 \mathrm{~g}}-T_{\mathrm{emp} 2 \mathrm{~s}}
\end{aligned}
$$

where, $\delta_{2 \mathrm{~g}}$ is considered zero in this study. $T_{\mathrm{emp} 2 \mathrm{~g}}$ and $T_{\text {emp2s }}$ are respectively the temperature in the stickysliding sub zone and its initial temperature. In this case it is the secondary shear temperature (sticky sub zone), displaced in the sliding-sticky sub zone during the chip evacuation.

Shear stress $\tau_{2 \mathrm{~g}}$ can be written:

$$
\begin{array}{r}
\tau_{2 \mathrm{~g}}=\left[\frac{A}{\sqrt{3}}+\frac{B \gamma_{d 2 \mathrm{~g}}^{n}}{\sqrt{3}^{n+1}}\right]\left[1+C \operatorname{Ln}\left(\frac{\gamma_{d 2 \mathrm{~g}}}{\dot{\gamma}_{d 0}}\right)\right] \\
\times\left[1-\left(\frac{T_{\text {emp2g }}-T_{\text {emp0 }}}{T_{\text {empmelt }}-T_{\text {emp } 0}}\right)^{m}\right]
\end{array}
$$

Consequently:

$$
T_{2}=\tau_{2 \mathrm{~s}} \frac{h}{\cos (\gamma *)} b+\frac{\tau_{2 \mathrm{~g}}}{2}\left(l_{c}-\frac{h}{\cos (\gamma *)}\right) b
$$

Now it can be allowable to compute the friction coefficient in the interface between the tool and chip as the ratio between $T_{2}$ and $N_{2}$ (Eq. (24)).

$$
\mu=\frac{T_{2}}{N_{2}}
$$

From this last equation it is possible to capture that it is not necessary to have the friction coefficient as a data input in the proposed analytical model.

In Table 2 are resumed the most important variables of the study using the presented analytical model.

The values of analytical forces and temperatures presented in Table 2 are similar to experimental ones (Tab. 1). Concerning the primary shear zone angle $\Phi$, the analytical calculation is accurate for cutting speeds over $126 \mathrm{~m} . \mathrm{min}^{-1}$. In particular $F_{y}$ and $l_{c}$ seem to be close to reality because the equivalent cutting angle $\gamma^{*}$ was introduced in the presented analytical model. In the case of $R=30 \mu \mathrm{m}$ (equivalent to $R=0 \mu \mathrm{m}) \gamma^{*}=-8.6^{\circ}$ and the vertical force value and contact length are higher than Merchant formulation.

\section{Numerical model}

Numerical simulations based on ABAQUS/Explicit were performed in order to both understand the physic of cutting and improve the analytic method.

The work piece (Fig. 5a) is numerically modelled in 3 parts [15]. In the part "final piece" only the behaviour law of Johnson and Cook is defined and for the "chip" and "transition" part the Johnson and Cook damage law [16] is also taken into consideration. Johnson and Cook behaviour and damage value are taken from Barge's study [13]. During numerical simulations was also adopted ALE formulation (Fig. 5b) in order to study more pertinently the cutting edge radius and vertical force $F_{y}$ effects. In this last case only Johnson and Cook behaviour law is used.

From a contact point of view, the Coulomb law was adopted and in particular it is considered that $\mu=0.39$ for $V_{c}=42 \mathrm{~m} \cdot \mathrm{min}^{-1}, \mu=0.30$ for $V_{c}=126 \mathrm{~m} \cdot \mathrm{min}^{-1}$, $\mu=0.25$ for $V_{c}=378 \mathrm{~m} . \mathrm{min}^{-1}$ according to the experimental results of Zemzemi [9]. Similar values are found with Equation (24) when the analytical approach is applied.

\subsection{Numerical setting}

After a mesh sensitivity study, a $10 \mu \mathrm{m}$ mesh size was adopted. Using a $10 \times 10 \mu \mathrm{m}$ mesh dimension and the previous friction coefficient, it is then possible to perform numerical simulations and compare results to experimental cutting forces (Fig. 6), primary shear zone angle $\Phi$, chip thickness $e_{\mathrm{c}}$ (Tab. 3).

In the presented $\mathrm{FE}$ simulations the deformation is supposed to be uniform. This assumption is justified by the manner of the calculation of the primary shear angle as a function of the feed rate divided by chip thickness.

For the different outputs presented, the numerical results are in concordance with the experimental ones. It is then considered that the present numerical model reproduces the real phenomena and will be use to calibrate further analytical cutting modelling.

From Table 4 it is possible to note also that the primary shear temperature value degreases when cutting speed grows up. This phenomenon is due to the close adiabatic conditions when the cutting speed is more than $126 \mathrm{~m} \cdot \mathrm{min}^{-1}$.

\subsection{Numerical validation of the equivalent cutting angle of $\gamma^{*}$}

In order to verify the equivalent cutting angle approach presented in the analytical model it is now proposed to apply the methodology of the equivalent cutting angle to the numerical problem (Fig. 7).

The real situation in terms of cutting edge radius and cutting angle is modelled with ALE, the equivalent cutting tool $\left(R=0\right.$ and $\left.\gamma^{*}\right)$ with a Lagrangian method. Comparative study is presented in Table 4. 
Table 2. Analytical results in case of AISI 4140 steel, carbide tool, cutting edge radius $30 \mu \mathrm{m}$ (equivalent to $R=0 \mu \mathrm{m}$ and $\left.\gamma^{*}=-8.6^{\circ}\right), h=0.15 \mathrm{~mm}$ (in brackets Merchant values).

\begin{tabular}{cccccccc}
\hline$V_{c}\left[\mathrm{~m} \cdot \mathrm{min}^{-1}\right]$ & $F_{x}[\mathrm{~N}]$ & $F_{y}[\mathrm{~N}]$ & $\Phi\left[{ }^{\circ}\right]$ & $l_{c} / f$ & $T_{\mathrm{emp} 1}\left[{ }^{\circ} \mathrm{C}\right]$ & $T_{\mathrm{emp} 2 \mathrm{~s}}\left[{ }^{\circ} \mathrm{C}\right]$ & $T_{\mathrm{emp} 2 \mathrm{~g}}\left[{ }^{\circ} \mathrm{C}\right]$ \\
\hline 42 & $1029(1447)$ & $591(434)$ & $33(26)$ & $3.02(2.12)$ & 432 & 911 & 1071 \\
126 & $981(826)$ & $512(207)$ & $35(33)$ & $2.81(1.7)$ & 485 & 960 & 1130 \\
378 & $949(699)$ & $474(140)$ & $36(34)$ & $2.74(1.57)$ & 509 & 1006 & 1171 \\
\hline
\end{tabular}

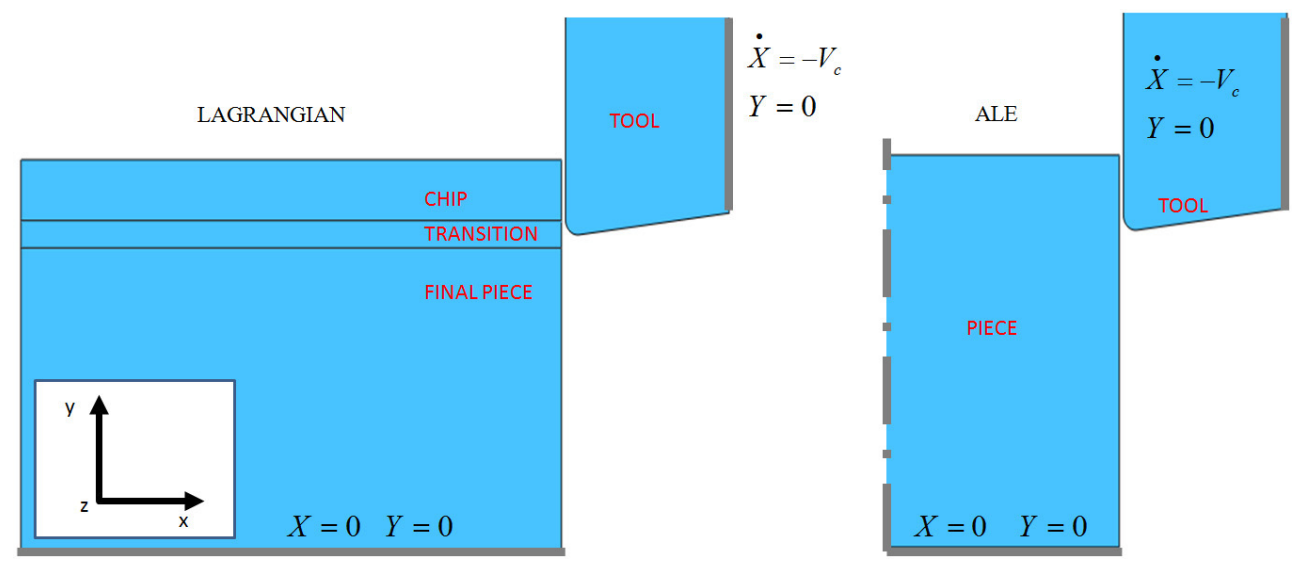

Fig. 5. Work piece modelling. Lagrangian and ALE formulation.

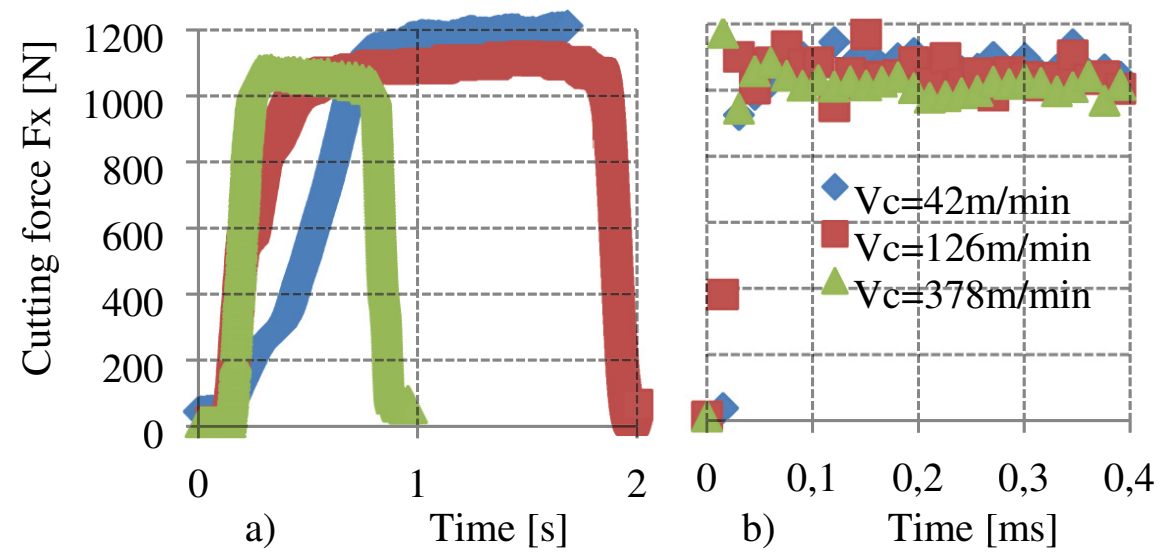

Fig. 6. Measured forces (a) and computed one's with FE Lagrangian formulation (b) versus time in the case of a mesh $10 \times 10 \mu \mathrm{m}$ for different cutting speeds, $h=0.15 \mathrm{~mm}$ and $\gamma=0^{\circ}$.

From this last table it is possible to capture that both ALE and Lagrangian values are similar. This means than the equivalent cutting angle approach is pertinent. Consequently Equation (2) can be considered realistic and can be used in the proposed analytical model.

Concerning results in the case of $R=150 \mu \mathrm{m}$, it is important to consider that the elastic phenomena under the tool are here important and the separation line between chip and work piece must be modelled. This approach is not presented in this paper [17].

\section{3 $\mathrm{N}_{2}$ computation and stresses distributions in zone 1 and 2}

In order to show how Equations (6) and (7) were built in the analytical section, a FE numerical calculation is adopted and the stress distribution in the four chip sections (Fig. 8) is investigated. The primary shear zone is delimited by Sections 1 and 3. Section 4 is the "interface" between tool and chip.

In Figures 9 and 10, the normal and tangential stresses distributions in the primary shear zone and the normal distribution in the secondary one are presented in the case of $h=0.15 \mathrm{~mm}, R=0 \mu \mathrm{m}, \gamma=0^{\circ}, \mu=0$.

In Figure $9, \sigma_{\mathrm{n} 1}$ distribution is similar in every chosen section inside the primary shear zone, close to the tool. In this zone the triaxiality is high. In the primary shear zone region close to the free surface, it is possible to capture the opposite situation; along section 1 the stress value is bigger and along Section 3 it is close to zero. In fact, in this last section, and close to the free surface, the chip is still formed and the effects of the compression in zone 2 are far. Consequently it is considered that the plastic strain 
Table 3. Numerical outputs in the case of AISI 4140 machining, tool in carbide material, $h=0.15 \mathrm{~mm}$ and $\gamma=0^{\circ}$. In brackets the ALE outputs $(R=30 \mu \mathrm{m})$.

\begin{tabular}{cccccc}
\hline$V_{\mathrm{c}}\left[\mathrm{m} \cdot \mathrm{min}^{-1}\right]$ & $F_{x}[\mathrm{~N}]$ & $F_{y}[\mathrm{~N}]$ & $\Phi\left[^{\circ}\right]$ & $l_{c} / h$ & $T_{\text {emp1 }}\left[{ }^{\circ} \mathrm{C}\right]$ \\
\hline 42 & $1150(1187)$ & $(571)$ & $25(26)$ & $1.9(2.1)$ & 509 \\
126 & $1090(1011)$ & $(556)$ & $31(30)$ & $1.5(1.6)$ & 571 \\
378 & $1070(982)$ & $(548)$ & $33(33)$ & $1.3(1.5)$ & 598 \\
\hline
\end{tabular}
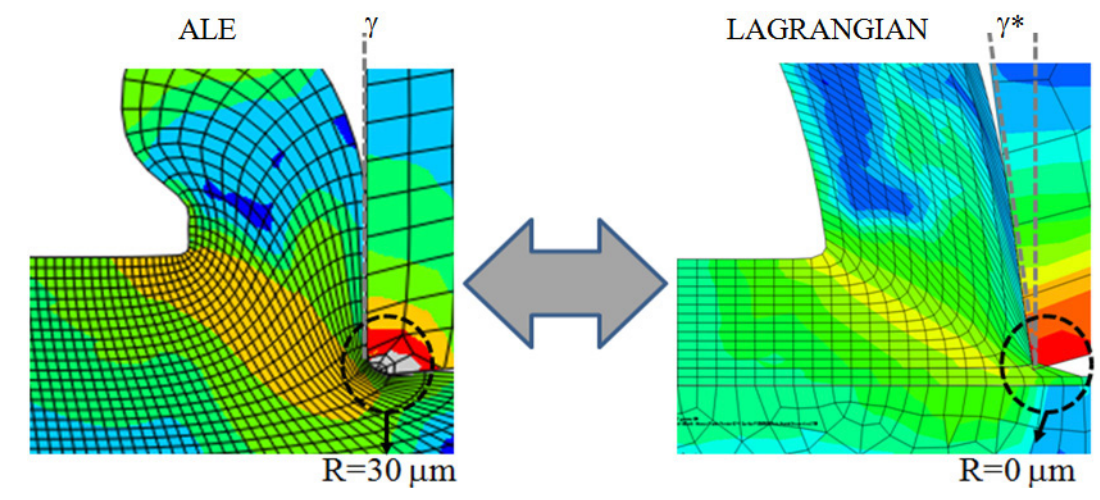

Fig. 7. Numerical validation of the equivalent cutting angle $\gamma^{*}$.

Table 4. Numerical results in case of AISI 4140 steel, carbide tool, $V_{c}=378 \mathrm{~m} \cdot \mathrm{min}^{-1}, h=0.15 \mathrm{~mm}$.

\begin{tabular}{ccccccc}
\hline$R\left[\mathrm{~m}_{\mathrm{min}}{ }^{-1}\right]$ & $F_{x}[\mathrm{~N}] \mathrm{ALE}$ & $F_{x}[\mathrm{~N}]$ Lagrangian & $F_{y}[\mathrm{~N}]$ ALE & $F_{y}[\mathrm{~N}]$ Lagrangian & $\Phi\left[^{\circ}\right]$ ALE & $\Phi\left[{ }^{\circ}\right]$ Lagrangian \\
\hline $30\left(R=0, \gamma=-8.6^{\circ}\right)$ & 821 & 836 & 184 & 195 & 33 & 35 \\
$70\left(R=0, \gamma=-20^{\circ}\right)$ & 912 & 919 & 451 & 463 & 30 & 30 \\
$150\left(R=0, \gamma=-45^{\circ}\right)$ & 1021 & 1122 & 824 & 891 & 26 & 22 \\
\hline
\end{tabular}

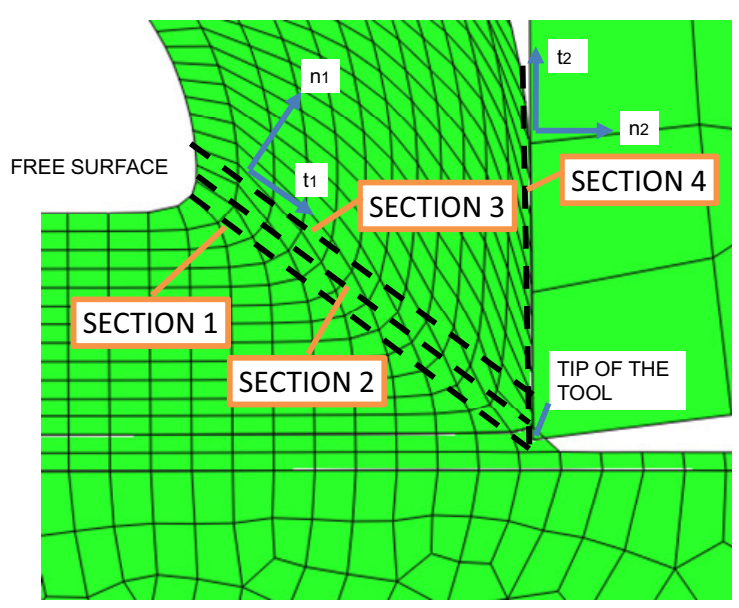

Fig. 8. Different sections employed in numerical simulations.

can be considered concentrated in the shear zones. This last hypothesis was made in the analytical section.

In the same way, the tangential stress distribution in the primary shear zone is quite similar in every chosen section close to the tool. In this case it is decided to formalize the uniform distribution for the analytical modelling.

In Figure 10, the normal stress distribution in the secondary shear zone is represented. For every condition there is a uniform part from the tip of the tool to the " $h$ " value and, from $h$ to $l_{c}$, the distribution becomes triangular. This is verified for three cutting speeds and, for different Johnson and Cook parameters, in the case of $V_{c}=378 \mathrm{~m} \cdot \mathrm{min}^{-1}$. Consequently, it is pertinent to formalise Equations (6) and (7) and Figure 4.

\subsection{Partition heat coefficient study}

Now, in order to validate if the adiabatic assumption in the primary and secondary shear zone was pertinent (analytical section), a comparative study between conductive and adiabatic formulation is presented (Fig. 11).

In this last figure it is possible to see that angles $\Phi$ are similar in the case of conduction and adiabatic conditions. Only for $V_{\mathrm{c}}$ close to $42 \mathrm{~m} \cdot \mathrm{min}^{-1}$ the high heat conduction in the chip and in the work piece let the temperature in zone 1 decreases and the softening effects are smaller. For this reason hardening effects are more important than softening and $\Phi$ is smaller in "conduction" conditions. For high cutting speeds or in the case of adiabatic calculation, the radius of the curvature of the chip is smaller. The chip material close to the interface is hot and "soft" and consequently there is a local elongation in the $Y$ direction. The hardening effects close to the tool tip are small and $\Phi$ stays with a high value.

Consequently, in the case of steel cutting, it can be pertinent to consider the coefficient heat factors $\delta_{1}, \delta_{2 \mathrm{~g}}$, $\delta_{2 \mathrm{~s}}$ equal to zero. 


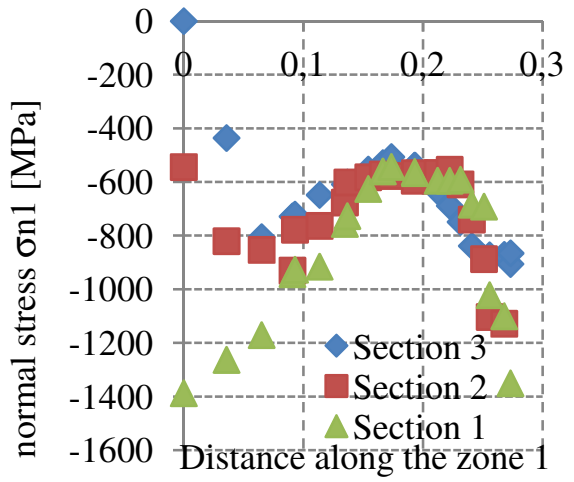

$[\mathrm{mm}]$

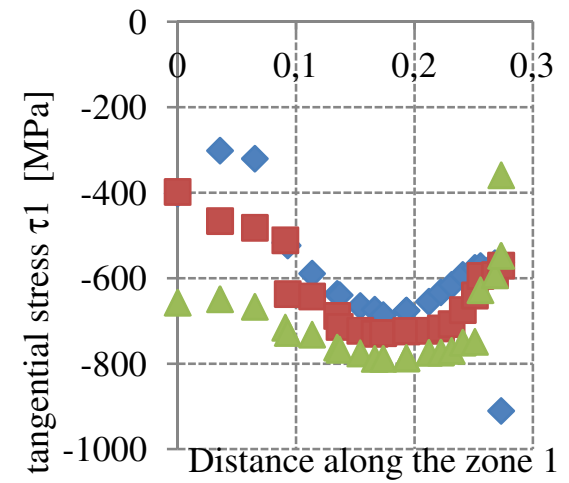

$[\mathrm{mm}]$

Fig. 9. Normal and tangential stress in the primary shear zone from the free surface (distance $=0)$ to the tool tip $($ distance $=$ $0.27 \mathrm{~mm})$ in the case $V_{\mathrm{c}}=378 \mathrm{~m} \cdot \mathrm{min}^{-1}$.
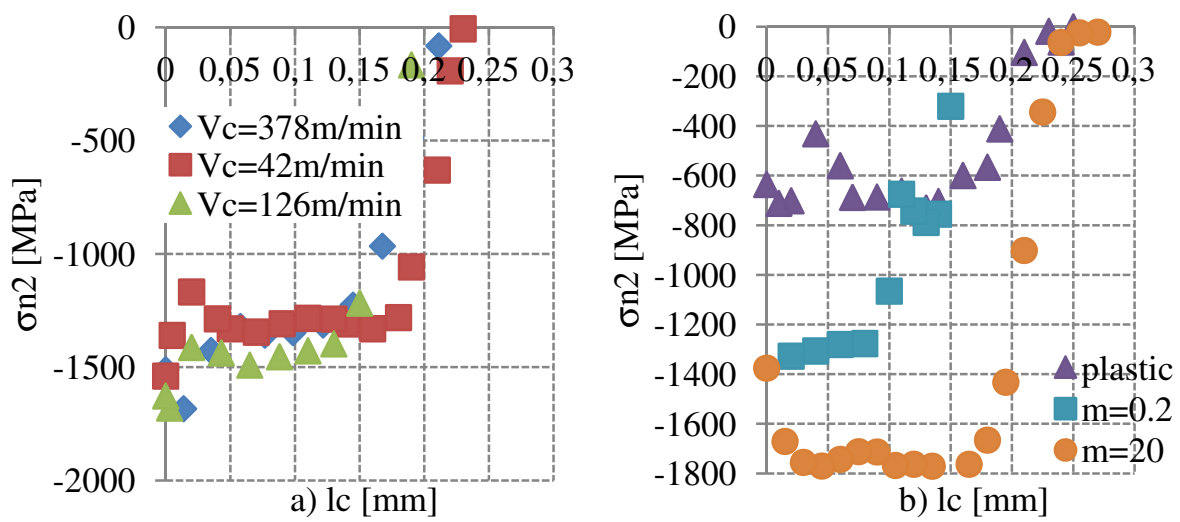

b) lc $[\mathrm{mm}]$

Fig. 10. Normal stress $\sigma_{\mathrm{n} 2}$ in zone 2 (Sect. 4). (a) different cutting speeds using the adopted behaviour law. (b) 2 different values of the $m$ exponent in Johnson and Cook with $V_{\mathrm{c}}=378 \mathrm{~m} \cdot \mathrm{min}^{-1}$.

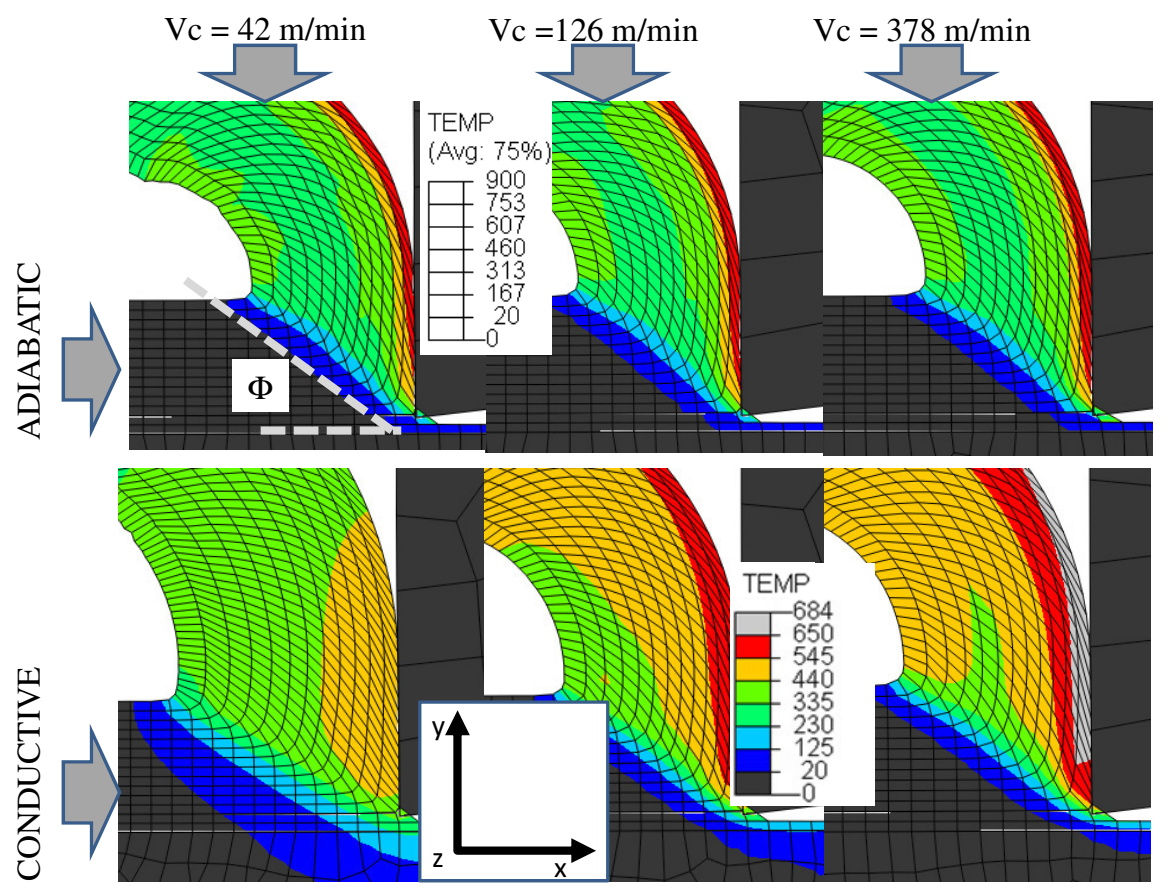

Fig. 11. Numerical simulations of temperatures $\left[{ }^{\circ} \mathrm{C}\right]$ during the chip formation in case of AISI 4140 steel and carbide tool. $h=0.15 \mathrm{~mm}, \mu=0$ and $\gamma=0^{\circ}$. Adiabatic and conduction calculation. 


\section{Discussion and conclusions}

In this paper an analytical model of chip formation is presented. It was fitted with FEM simulations and verified with experimental tests.

The chip is considered rigid and the static equilibrium of the chip leads to the definition of three simple equations like Merchant. The thermo-mechanical assumption was made in the shear zones 1 and 2 where the strain is supposed to be concentrated, and the partition heat factor is considered negligible after FE study. The stress distribution is numerically studied and the outputs of this investigation were acted in new formulations based on triaxiality and forces distributions applied to the chip.

The temperature calculation is made using the definition of the specific heat in the shear zones. In this paper only the primary shear zone was investigated.

The cutting radius of the tool is modelled using an equivalent cutting angle which is new compared to the pre-cited works. The $f / R$ ratio is important and defines 2 different conditions. If it is high the cutting radius $R$ can be considered null, but if it is low, it is necessary to model the radius $R$. It is the industrial case of damaged tools.

The calculations of the variables of the model are only function of the input parameters (process parameters and thermo-mechanical data) and no experimental settings like chip thickness measurements are required. In particular the friction coefficient $\mu$ at the tool-chip interface is calculated.

The analytical equations can be directly used for industrial application or for scientific purpose, in order to have easier data to understand the removal material problem before a more intense research.

As outlooks it is suggested to model analytically residual stresses in the final piece in order to have quickly some indications. This approach can be completed with numerical or experimental study [18].

\section{References}

[1] M.E. Merchant, Mechanics of the metal cutting process. I. Orthogonal cutting and a type 2 chip, J. Appl. Phys. (USA), Amer. Inst. Phys. New York 16 (1945) 267-275

[2] M.E. Merchant, Mechanics of the metal cutting process. II. Plasticity conditions in orthogonal cutting, J. Appl. Phys. (USA), Amer. Inst. Phys. New York 16 (1945) 318324

[3] E.H. Lee, B. Shaffer, The theory of plasticity applied to problems of machining, J. Appl. Mech. Amer. Soc. Mech. Eng., New York 18 (1951) 405-413
[4] P. Gilormini, E. Felder, Modélisation thermomécanique de la formation du copeau en usinage à grande vitesse, Bulletin du Cercle des Métaux, Tome 15, 1985

[5] P.L.B. Oxley, Mechanics of machining an analytical approach to assessing machinability, Ellis Horwood limited, Chichester, 1989

[6] A. Moufki, A. Devillez, D. Dudzinski, A. Molinari, Thermodynamical modeling of cutting and experimental validation, Metal Cutting and High Speed Machining (2002) 51-67

[7] A. Molinari, R. Cheriguene, H. Miguelez, Numerical and analytical modeling of orthogonal cutting: The link between local variables and global contact characteristics, Int. J. Mech. Sci. 53 (2011) 183-206

[8] F. Salvatore, T. Mabrouki, H. Hamdi, Numerical simulation and analytical modelling of ploughing and elastic phenomena during machining processes, Int. J. Surf. Sci. Eng. 6-3 (2011) 185-200

[9] F. Zemzemi, Caracterisation de modèles de frottement aux interfaces pièce-outils-copeau en usinage : application au cas de l'usinage des aciers et de l'inconel 718, Thèse, École centrale de Lyon, 2007

[10] G.R. Johnson, W.H. Cook, A constitutive model and data for metals subjected to large strains, strain rates and high temperature, 7th Int. Symp. Ballistics (1983) 541-547

[11] A. Moufki, A. Molinari, A new thermomecanical model of cutting applied to turning operations. Part I. Theory, International J. Machine Tools Manuf. 45 (2005) 166-180

[12] A. Moufki, A. Molinari, A new thermomecanical model of cutting applied to turning operations. Part II. Parametrical Study, Int. J. Machine Tools Manuf. 45 (2005) 181-193

[13] M. Barge, H. Hamdi, J. Rech, J.M. Bergheau, Numerical modelling of orthogonal cutting: influence of numerical parameters, J. Mater. Proc. Technol. 164-165 (2005) $1148-1153$

[14] A. Molinari, D. Dudzinski, Stationnary shear band in high speed machining, C.R. Acad. Sci. Paris 315/2 (1992) 399-405

[15] T. Mabrouki, J.F. Rigal, A contribution to a qualitative understanding of thermo-mechanical effects during chip formation in hard turning, J. Mater. Proc. Technol. 176 (2006) 214-221

[16] G.R. Johnson, W.H. Cook, Fracture characteristics of three metals subjected to various strains, strain rates, temperatures and pressures, Eng. Fract. Mech. 21 (1985) 31-48

[17] F. Salvatore, Contribution à la modélisation analytique et numérique de l'enlèvement de matière et de ses conséquences induites : cas de la coupe orthogonale, Thèse, École Nationale Supérieure des Mines de SaintÉtienne, 2011

[18] F. Salvatore, T. Mabrouki, H. Hamdi, Numerical and experimental study of residual stresses induced by machining processes, Int. J. Surf. Sci. Eng. 6-1/2 (2012) 136-147 